\title{
Cost-Effectiveness Analysis of Establishing a Distance-Education Programme for Health Personnel in Swaziland
}

\author{
Joses M. Kirigia ${ }^{1 *}$, Luis G. Sambo ${ }^{1}$, Margaret Phiri $^{3}$, Gladys Matsembula ${ }^{4}$ and Magda Awases ${ }^{1}$
}

1. World Health Organization Regional Office for Africa, Parirenyatwa Hospital, P. O. Box BE773, Harare, Zimbabwe> Tel: +263-91-238563. Email: (kirigiaj@whoafr.org), 2. WHO Country Office, Swaziland, 3. Ministry of Health and Social Welfare, Swaziland.

* To whom correspondence should be addressed.

\begin{abstract}
SUMMARY
There is a growing conviction among policy-makers that the availability of adequate numbers of well-trained and motivated human resources is a key determinant of health system's capacity to achieve their health, responsiveness and fairness-improving goals. The objective of this study was to estimate the cost, effectiveness and incremental costeffectiveness ratios of various distance-education strategies for the health sector in Swaziland; and recommend the most cost-effective option. The distance-education strategies evaluated included: Mobile library services (MLS); micro-resources centers WITHOUT video conferencing in five health centers and four regional hospitals (MRC-VC); microresources centers WITH video conferencing in five health centers and four regional hospitals (MRC+VC); centralized resource center WITHOUT video conferencing (CRC-VC); centralized resource center WITH video conferencing ( $C R C+V C$ ); and status quo (SQ). The incremental cost-effectiveness ratio for MLS was Emalangeni (E) 41,846; MRC-VC was E42,696; MRC+VC was E45,569; CRC-VC was E43,578; CRC+VC was E40,827; the latter being the most cost-effective distance-education strategy. According to policy-makers, this study served to clarify the various distance-education strategies, their costs and their benefits/effectiveness. There is a need for developing in Africa a culture of basing policy and management decisions of such kind on systematic analyses. Of course, economic evaluation will, at most, be a guide to policy- and decision- making, and thus, the onus of decision making will always be on policy-makers and health-care managers.
\end{abstract}

[Afr. J. Health Sci. 2002; 9: 3-15]

\section{Introduction}

"The fortieth world Health Assembly (in 1987), urged Member States: to ensure that manpower is not only adequately planned for and trained, but also skilfully managed, including the improvement of career development and incentive schemes, to ensure its most effective utilization." [1].

Various resolutions of the World Health Assembly [1-6] and the WHO Regional Committee for Africa [7-10] have underscored the paramount role of health personnel in the implementation of national health development policies and plans. While endorsing the regional strategy for the development of human resources for health in Africa, the Regional Committee, in
1998, urged Member States to support efforts to improve the education, training and utilization of health personnel and the regulation of the health profession [10].

It is therefore not surprising that ministers of health of African national have continued to take keen interest in human resource development for health. Approximately $70 \%$ of the recurrent budget of the health sector in many countries is expended on health personnel, and the efficiency in the use of the remaining $30 \%$ budget plus capital investments are largely dependent on them [11]. In all health-care systems, human resources play a prominent role in combining their time and other inputs (e.g. 
pharmaceuticals, non-pharmaceutical supplies, medical equipment, vehicles, building) to produce health care [12]. Thus, the extent to which a health system succeeds in meeting its goals of enhancing the health status of its populations, responding adequately to people's legitimate non-medical expectations, and financing itself fairly [13], hinges greatly on the quantity and quality of its human resources.

In the African Region, for a number of reasons, training is a vital component of the health sector's human resource development strategies. Firstly, the Region is particularly prone to the increasing burden of brain drain and attrition of health personnel due to HIV/AIDS epidemic [14]. The former signals the need for taking measures geared towards increasing the retention of staff, probably through the enhancement of skills and career development of various categories of health personnel, while the latter calls for the training of more people to replace those leaving the service due to incapacity or death. Secondly, training is expected to enable health systems to reap the following benefits: greater productivity and quality; less wastage of inputs (e.g. pharmaceuticals, non-pharmaceutical supplies, human resource time, etc.); greater versatility and adaptability to new methods; less need for close supervision; fewer accidents when providing care; and greater job satisfaction manifested in lower labour turnover and less absence [15]. Thus, training will equip health personnel with positive attitudes towards patients, skills and knowledge of diseases, their diagnosis, treatment and prevention, leading to increased human motivation, and ultimately translating into increased quality and quantity of care provided to patients. There is evidence from Europe that dissatisfaction with promotion and training opportunities had a stronger impact than workload or pay [16].

In 1989, the Regional Committee requested Member States "to strengthen procedures which would enable certain schools or faculties of medicine in the Region to work together to establish subregional and regional facilities for postgraduate studies in the health sciences"[7]. It simultaneously requested the WHO Regional Director "to pay special attention to the countries where it is not possible for the moment to set up schools of medicine with a view to giving them support in the search for solutions, particularly in the framework of the African Region and in the spirit of Technical cooperation among Developing countries" [7]. Some African countries, like Swaziland, do not have medical schools. However, given the availability of satellite communication technologies today, such countries could continually upgrade the competencies of their health sector's human resources by tapping into courses conducted by medical schools in developed or other developing countries.

The labour force in the Ministry of Health and Social Welfare (MoHSW) was estimated at 4000 persons during 2000. That number comprised approximately 186 doctors, 3000 registered nurses, 600 nursing assistants, 60 enrolled nurses, 12 laboratory technologists, 8 laboratory technicians, 8 laboratory assistants and about 122 other cadres. The majority of the staff were stationed in regional hospitals, health centers and clinics where there is limited access to further education and training. The isolation of having to work in a distant place without the benefit of Jearning about new developments in the health field (including medicines, procedures, algorithms, diagnostic techniques, etc.) could easily erode the quality of services rendered to communities [17].

In June 2000, the MoHSW undertook a training needs assessment. The study covered a sample of 446 personnel at national, regional, health-centre and rural-clinic levels. Approximately $38 \%$ of them reported to have received no training during the last three years and above. The following priority learning needs identified: health planning and management; health systems research; quality assurance; general nursing and midwifery; team building; epidemiology; leadership development; public health; human resources managements; case management; family planning; health education; and laboratory science and technology [18]. The respondents identified the following as the strategies that would best meet their training needs: full-time residential training outside the country; full-time non-residential training within 
the country; in-service training in local institutions; and distance education (nonresidential) offered by institutions of higher learning in neighbouring countries. Given the scarcity of manpower at the service delivery points in Swaziland, distance education was seen to be the most preferred system by MoHSW policy-makers since it would have the least negative effect on service provision. This is why the MoHSW is encouraging practicing staff to pursue further studies through this strategy.

Swaziland's framework of agreement on the distance- and continuing-education programme (DCEP) for the MoHSW spells out its aims and objectives, expected outcomes of the programme, guiding principles for the implementation of the programme, the roles and responsibilities of the partners (MoHSW and WHO/Swaziland), programme management, programme monitoring and evaluation, resource mobilization, and procedure of arbitration in case of any dispute between partners [19].

In order to facilitate planning and resource mobilization, the MoHSW and the WHO Country Office commissioned an economic evaluation for identifying the most cost-effective option for making distance- and continuingeducation opportunities amenable to the majority of health and social welfare staff stationed in different parts of the country. Thus, the aim of the current study was to recommend the most cost-effective mode of increasing the accessibility of distance-learning opportunities to all health sector staff with a capacity to benefit.

A working group composed to a health economist, a human resource development expert and a public health expert was constituted by the Minister of Health and Social Welfare and the WHO Country Representative in Swaziland to address the following question: "From the viewpoint of both the MoHSW and students, is it more cost-effective to deliver distance-education either via mobile library services (MLS); micro-resource centers WITHOUT video conferencing in the five health centers and four regional hospitals (MRC-VC); micro-resource centers WITH video conferencing in the five health centers and four regional hospitals (MRC+VC); centralized resource center WITHOUT video conferencing (CRC-VC); centralized resource center WITH video conferencing $(\mathrm{CRC}+\mathrm{VC})$; or status quo (SQ), i.e. ad hoc registration of students with various collaborating institutions?"

The specific objectives of this study were: to estimate the cost of each of the options mentioned above; to stimulate the effectiveness of each of the options being appraised; to estimate the incremental cost-effectiveness ratios of each alternative option; and to recommend the most cost-effective option.

\section{Methods}

\section{Proposed organizational structure of DCEP}

In Swaziland, the Ministry of Education (MoE) is responsible for the formal (largely basic) training of human resources for health and other sectors, while the Ministry of Public Services and Information (MoPSI) is in charge of inservice training, including distance and continuing education. However, during the interviews, a substantive number of policymakers and staff at the MoHSW recommended that, since a majority of the potential beneficiaries were health sector workers, DCEP should be situated within the MoHSW.

The study team proposed that DCEP be managed by three bodies, namely; a programme steering committee (PSC), a technical programme committee (TPC), and a programme secretariat (PS). The suggested membership, terms of reference and frequency of meetings for the three bodies are detailed below.

\section{Programme steering committee (PSC)}

The goal of PSC would be to provide policy direction and cultivate a conducive environment within which the health sector's human resource capacity could be created and strengthened over time. Through its multisectoral membership and work, PSC would probably set a multisectoral collaborative example that could be emulated in other governmental contexts, and definitely, in other countries within the WHO African Region. 
The membership of PSC would consist of the relevant under-secretaries in the MoHSW, MoE, MoPSI, Ministry of Development and Economic Planning (MoDEP), Ministry of Finance (MoF); WHO national management professional; and programme coordinator (secretary of PSC)

The terms of reference of PSC would be to: provide policy direction; advocate for the inclusion of DCEP in the national policy framework, the national development plan and the human resource development plan; oversee the overall running of the programme, including the operations of TPC and the secretariat; develop and implement sustainable mechanisms for financing the programme without being over-dependent on external donations; market the programme to health sector staff, the government, the King, the private sector and external human development partners, including United Nations agencies, Bretton Woods institutions (the World Bank and the International Monetary Fund) and bilateral agencies; allocate scholarships on the basis of merit and need; and monitor and evaluate performance.

Given the multiplicity of commitments of the membership of PSC to other national development programmes, it would be advisable to keep its meetings related to the programme to a minimum. Thus, it is proposed that the body should have a two-day retreat once every year. To ensure the undivided attention of all PSC members during the retreat period, it would be advisable to hold them outside the city. And, to cultivate team spirit, it would be vital for the OSC members to travel in the same vehicle to and from the retreat site.

\section{Technical programme committee (TPC)}

The goal of TPC would be to contribute towards the achievement of the national health sector's human development targets by ensuring the efficient management of DCEP.

The membership of TPC will consist of the relevant officers from the faculties of health sciences and of education at the University of Swaziland; the Nazaren College of Nursing; the Good Shepherd School of Nursing; the human resource development officer from the MoHSW (e.g. training officer); sectoral officers from the MoE, MoPSI, MoDEP, and MoF; SADC focal point for education or health; WHO national management professional; and programme coordinator (as secretary).

The terms of reference of TPC would be to: translate national human resource development policies into action plans; assess national healthrelated training needs based on national health needs; identify accredited collaborating distance-learning institutions; identify student promoters/mentors; conduct advocacy (marketing) related to the programme; determine additional resource requirements for enhancing the effectiveness of the programme; monitor and evaluate the use of resources, and progress made in realizing the objectives of the programme; ensure the implementation of policy decisions taken by PSC; keep PSC informed of its own activities (including meetings) and those of the secretariat; and carry out any other relevant functions allotted by PSC.

The TPC would hold two retreats per year at a venue outside the city. Each of the retreats will be for a duration of two days.

\section{Programme secretariat (PS)}

The goal of programme secretariat (PS) would be to contribute towards the achievement of the national health sector human resource development targets through efficient day-to-day implementation of DCEP.

The membership of PS would consist of: one programme coordinator (with post-graduate degree in education and experience in conducting distance education programmes); one librarian (with competencies in information technology - including management of virtual libraries - and management of health servicesrelated information); one administrative officer/assistant; one secretary-cum telephonist; one messenger; and one driver.

The terms of reference of PS would involve: day-to-day running of the programme, which would include receiving learning materials from collaborating institutions, disseminating learning materials to students, reminding students of outstanding tuition and examination fees owed to the collaborating institutions, 
disseminating information related to dates and venues of examinations, receipt and invigilation of examinations, and facilitating communication between students, mentors and collaborating institutions, identification of potential students (i.e. those with a capacity to benefit from the programme); establishment of an up-to-date databank of actual and potential mentors; matching of students with appropriate collaborating institutions and courses; matching of students with relevant mentors; acting as the liaison between collaborating institutions and the programme, management of human, financial and capital assets (e.g. computers, printers, video-conferencing equipment, vehicles, etc.) of the programme; administration of scholarships; compiling and submission of annual reports to managerial organs of the programme and donors; preparation of PSC and TPC retreats/meetings (including dissemination of minutes of all PSC and TPC meetings to relevant people); implementation of policy and administrative decisions of PSC and TPC; cultivating computer literacy among students and mentors (where there is expressed need); guidance and counseling of students in need; maintaining physical and virtual (electronic) libraries of relevant learning materials, e.g. online journals; identification and acquisition of learning materials; mobilizing resources (including scholarships/training grants) for the programme; marketing of the programme using various forms of media; and ensuring that those in need (i.e. with capacity to benefit) reap maximum benefit from the programme.

\section{Description of alternative options for delivering DCEP}

The costs and outputs of the following six strategies were appraised:

a. Status quo (SQ)

This option refers to the current ad hoc registration of students with various collaborating institutions. Currently, the students identify potential universities on their own, communicate directly with the universities, and identify potential local promoters/supervisors/mentors.

b. Mobile library services (MLS)
The option entails establishing a programme office (with a programme coordinator, a librarian, an administrator, a secretary-cumtelephonist, a messenger-cum-cleaner, and a driver) and operating a mobile library service to each of the regional health centers on monthly basis. The mobile library van would be equipped with a computer with Internet facilities (through which online journals and training materials could be accessed), latest textbooks and journals.

c. Centralized resource center WITHOUT video conferencing (CRC-VC)

This option requires the establishment of a resource center at Mbabane, i.e. the Capital city. The center would have Internet facilities, textbooks and hard and online copies of key journals. In addition, the programme secretariat would provide all the services mentioned in its terms of reference. This option would imply that those who wish to consult the center will have to travel from their workplace to Mbabane to use the resources.

d. Centralized resource center WITH video conferencing (CRC+VC)

This option entails the establishment of a resource center at Mbabane. The center would have video conferencing facilities, Internet facilities, textbooks and hard and online copies of key journals. In addition, the programme secretariat would provide all services mentioned in its terms of reference. This option would imply that those who wish to consult the center will have to travel from their workplace to Mbabane to use the resources.

e. Micro-resource centers in the 5 health centers and 4 regional hospitals WITHOUT video conferencing (MRCVC) This option entails the establishment of micro-reosurce centers at the five health centers and four regional hospitals. Each resource center would have Internet facilities, textbooks 
and hard, and online copies of key journals. All resource centers would be supported by the programme secretariat based at the MoHSW in Mbabane.

f. Micro-resource centers in the 5 health centers and 4 regional hospitals WITH video conferencing ( $\mathrm{MRC}+\mathrm{VC}$ )

This option involves the establishment of micro-resource centers at the five health centers and four regional hospitals. Each resource center would have video conferencing facilities, Intemet facilities, textbooks and hard and online copies of key journals. All resource centers would be supported by the programme secretariat based at the MoHSW in Mbabane.

It is important to note that all the alternative options, except the status quo, would require the services of PSC, TPC and PS. In addition, the resources required in running the three bodies would be equal across all the alternative options.

Conceptual framework for the cost-effectiveness analysis of DCEP strategies

Identification and measurement of costs of various alternatives

The costs of an education programme are taken to be the resources it uses up. Drummond et al (20) delineate three types of costs: organizing and operating costs within the health sector; costs borne by beneficiaries and their families; and costs borne by others. This study took into account the following direct costs:

- Costs to the government of organizing and operating the distance- and continuingeducation programme, which include recurrent and capital costs. The recurrent costs include personnel time, accommodation, lunch, dinner, transport, material, utilities (i.e. electricity, water, telephone), email charges, satellite time charges, maintenance (of vehicles, equipment and buildings), textbooks, printed journals' subscriptions, and online journal subscriptions. The quantities and market prices of these inputs were obtained through interviews with relevant experts.
- Capital costs refer to the value of those programme inputs which had a useful life of more than one year, e.g. computers, printers, video conferencing (VC) equipment, vehicles and buildings. We assumed a useful life of 10 years for computers, printers, VC equipment, furniture and vehicles; and an interest rate of $10 \%$ [21]. The size of the resource center and quantities of equipments and furniture required were obtained from a study undertaken in Eritrea by Steyn and Human [22] and PictureTel Corporation [23]. The prices or replacement values of video conferencing equipment and computers were obtained from the DIMENSION DATA [24]. Except for buildings, we obtained the annual equivalent cost of other capital inputs by dividing their replacement values by an annuity equivalent cost of other capital inputs by dividing their replacement values by an annuity factor. For buildings we used the local market annual space rent per square metre.

- Costs borne by standards under various distance-education strategies, e.g. registration fees, tuition fees, fee for course materials, examination fees, research supervision fees and students' communication expenses. The student fees were obtained by administering a questionnaire to a sample of students currently enrolled for distance education in Swaziland.

The study team were also able to estimate the indirect costs, i.e. the time likely to be invested in studies by interviewing health sector students in Swaziland currently enrolled in distanceeducation programmes. This included the number of working and after-work hours spent on matters related to distance-education programme, e.g. reading, researching, writing assignments, communicating, taking tests, writing dissertations, group discussions, consulting resident promoters/supervisors, etc. The private after-work time has got an opportunity cost since it would have been invested in leisure activities (e.g. socializing with relatives and friends, church-related 
activities, traditional dancing, sports, watching movies, etc.), relaxing with family, assisting children with their home work, caring for the family (e.g. bathing children, laundry, cooking, etc.), or working late in the office/health facility. The time invested in studies was valued at the prevailing MoHSW wage rate. The annual remunerations (salary and fringe benefits) for the concerned staff were divided by the total number of working hours per year (i.e. 261 working days in a year times 8 hours per day) to obtain the hourly wage rate.

Identification and measurement of the effectiveness of each alternative

The measurement of the effectiveness of alternatives involves two interrelated steps: deciding which outcome criteria to use, and developing specific measures for those criteria [25]. A criterion is a characteristic, rule or test used to make judgement about an alternative (e.g. distance-education programme enrollees). A measure is a number assigned to that criterion (e.g. the percentage of health and social welfare staff within the target population successfully enrolled in distance-education programme).

In this study, estimation of the effectiveness of various options involved three steps:

1. Identification of target population in year $t\left(N_{i}\right)$ : This was the number of health and social welfare staff in need of capacity-strengthening through distance education. Since during the training needs assessment all the respondents expressed the need for further training, we assumed that the total number of health and social welfare staff, estimated at 4000 , would be the target population for the DCEP.

2. Estimation of expected proportion of the target population likely to enroll $\left(P_{i}\right)$ : Using a Modified Delphi Technique [26, 27], an anonymous panel of five experts from the MoHSW and the University of Swaziland (Faculty of Health Sciences and Institute of Distance Educations) was given a selfadministered questionnaire asking them to subjectively judge the expected percentage/proportion $\left(\mathrm{P}_{\mathrm{i}}\right)$ of the target population likely to enroll into the distance-education porgrmme if each of the options were to be implemented singly.

3. Impact (I) assessment: The same experts mentioned above were asked to subjectively assess, on a scale of $0 \%$ (totally ineffective) to $100 \%$ (perfectly effective), the expected impact $\left(I_{i}\right)$ of each alternative strategy in imparting knowledge, developing skills, motivating and modifying service provision-related behaviour.

4. Calculation of effectiveness index $\left(E_{i}\right)$ : this index was calculated using the following formula:

$$
\mathrm{E}_{\mathrm{i}}=\mathrm{N}_{\mathrm{t}} \times \mathrm{P}_{i} \times \mathrm{I}_{i}
$$

where $E_{i}$ is the effectiveness of $i^{\text {th }}$ strategy; $\mathrm{N}_{\mathrm{t}}$ is the target population of health and social welfare workers in year $\mathrm{t}: \mathrm{P}_{\mathrm{i}}$ is the proportion expected to enroll the programme if $i^{\text {th }}$ strategy is in place; and $I_{i}$ is the impact of $i^{\text {th }}$ strategy. For example, assuming that $\mathrm{N}_{\mathrm{t}}$ is $4000, \mathrm{P}_{\mathrm{i}}$ is $10 \%$, and $I_{i}$ is $40 \%$; then the effectiveness of the $i^{\text {th }}$ option would be: $E_{i}=4000 \times 0.10 \times 0.40+160$ health sector personnel. In this hypothetical example, 160 is the number of staff who will be enrolled and whose knowledge, skills and health service provision behaviour would be positively modified.

As mentioned earlier, data on $P_{i}$ and $I_{i}$ were obtained from a sample of educational experts, following the following procedure:

- appointments were made by telephone with each of the experts;

- during the day of the appointment, the study team met the experts in their offices to explain the purpose of the exercise and to deliver the questionnaire;

- they were requested to go through the questionnaire in the presence of the study team and ask questions for clarification;

- they were then left to evaluate the effectiveness of the six distanceeducation strategies; 
and

- after a few days, the team went back to collect the questionnaire.

The cost-effectiveness criteria

The expected total costs to both the MoHSW (i.e. the employer) and students are defined as $\mathrm{TC}_{1}$; and the expected total effectiveness as $\mathrm{TE}_{\mathrm{i}}$ where $\mathrm{i}$ denotes the distance-education strategy being evaluated. Taking partial differential of the expected $T C_{1}$ and $T E_{i}$ of $i^{\text {th }}$ strategy with respect to those of the status quo (SQ), the incremental costs $\left(\partial \mathrm{TC}_{\mathrm{i}}\right)$ and effectiveness $\left(\mathrm{TE}_{\mathrm{i}}\right)$ can be obtained as follows: $\partial \mathrm{TC}_{\mathrm{i}}=\mathrm{TC}_{\mathrm{i}}-\mathrm{TC}_{\mathrm{SQ}}$, where $\mathrm{TC}_{\mathrm{SQ}}$ is the total cost of $\mathrm{SQ}$ strategy; $\partial \mathrm{TE}_{\mathrm{i}}$ $=T E_{\mathrm{i}}-\mathrm{TE}_{\mathrm{SQ}}$, where $\mathrm{TE}_{\mathrm{SQ}}$ is the total effectiveness of the SQ strategy. The incremental cost-effectiveness ratio $\left(\mathrm{CER}_{i}\right)$ for the $i^{\text {th }}$ strategy can be expressed as follows:

$\mathrm{CER}_{1}=\partial \mathrm{TC}_{\mathrm{i}} / \partial \mathrm{TE}_{\mathrm{j}}$.

Similarly, the incremental CER for various distance education strategies appraised in this study were obtained as follows:

(i) Micro-resource centers WITH video conferencing $(M R C+V C)$

$\mathrm{CER}_{\mathrm{MRC}}+\mathrm{vC}=(\mathrm{TC} \mathrm{MRC}+\mathrm{vC}-$ $\left.\mathrm{TC}_{\mathrm{SQ}}\right) /\left(\mathrm{TE}_{\mathrm{MRC}}+\mathrm{vC}-\mathrm{TE}_{\mathrm{SQ}}\right)=\partial \mathrm{TC} \mathrm{MRC}_{\mathrm{M}}$ ${ }_{v C} / \partial T E E_{M R C}+v_{C}$, where CER MRC + vc is the incremental cost-effectiveness ratio, TCMRC + VC is the total cost, $\mathrm{TE}_{\mathrm{MRC}}+$ $\mathrm{vC}_{\mathrm{C}}$ is the total effectiveness, $\partial \mathrm{TC}_{\mathrm{MRC}}+\mathrm{vC}$ Is the incremental cost and $\partial \mathrm{TE}_{\mathrm{MRC}+\mathrm{VC}}$ is the incremental effectiveness of the $\mathrm{MRC}+\mathrm{VC}$ strategy.

(ii) Micro-resource centers WITHOUT video conferencing (MRC-VC)

$\mathrm{CER}_{\text {MRC-VC }}=\left(\mathrm{TC}_{\mathrm{MRC}-\mathrm{VC}}-\right.$ $\left.\mathrm{TC}_{\mathrm{SQ}}\right) /\left(\mathrm{TE}_{\mathrm{MRC}-\mathrm{VC}}-\mathrm{TE}_{\mathrm{SQ}}\right)=\partial \mathrm{TC}_{\mathrm{MRC}}$. ${ }_{v c} / \partial T E_{\text {MRC-vC, }}$ where $C E R_{\text {MRC-vC }}$ is the incremental cost-effectiveness ratio, $\mathrm{TC}_{\mathrm{MRC}-\mathrm{VC}}$ is the total cost, $\mathrm{TE}_{\mathrm{MRC}-\mathrm{VC}}$ is the total effectiveness, $\partial \mathrm{TC}_{\mathrm{MRC} \cdot \mathrm{VC}}$ is the incremental cost and $\partial \mathrm{TE}_{\mathrm{MRC}}-\mathrm{vC}$ is the incremental effectiveness of the MRCVC strategy. (iii) Centralized resource center WITH video conferencing $(C R C=V C)$

$\mathrm{CER}_{\mathrm{CRC}-\mathrm{VC}}=\left(\mathrm{TC}_{\mathrm{CRC}-\mathrm{VC}}-\mathrm{TC}_{\mathrm{SQ}}\right) /\left(\mathrm{TE} \mathrm{E}_{\mathrm{CRC}}\right.$. $\left.\mathrm{vC}-\mathrm{TE}_{\mathrm{SQ}}\right)=\partial \mathrm{TC}_{\mathrm{CRC}-\mathrm{vC}} / \partial \mathrm{TE} \mathrm{CRC}_{\mathrm{C}} \mathrm{v}_{\mathrm{C}}$, where $\mathrm{CER}_{C R C=V \mathrm{C}}$ is the incremental cost-effectiveness ratio, $\mathrm{TC}_{\mathrm{CRC}-\mathrm{V}_{C}}$ is the total cost, $\mathrm{TE}_{\mathrm{CRC}-\mathrm{VC}}$ is the total effectiveness, $\quad \partial \mathrm{TC}_{\mathrm{CRC}-\mathrm{VC}}$ is the incremental cost and $\partial \mathrm{TE}_{\mathrm{CRC}-\mathrm{VC}}$ is the incremental effectiveness of the CRC. VC strategy.

(v) Mobile library services (MLS)

$\mathrm{CER}_{\mathrm{MLS}}=\left(\mathrm{TC}_{\mathrm{MLS}}-\mathrm{TC}_{\mathrm{SQ}}\right) /\left(\mathrm{TE}_{\mathrm{MLS}}-\right.$ $\left.\mathrm{TE}_{\mathrm{SQ}}\right)=\partial \mathrm{TC}_{\mathrm{MLS}} / \partial \mathrm{TE}_{\mathrm{MLS}}$, where CER $\mathrm{R}_{\mathrm{MLS}}$ is the incremental cost-effectiveness ratio, $\mathrm{TC}_{\mathrm{MLS}}$ is the total cost, $\mathrm{TE}_{\mathrm{MLS}}$ is the total effectiveness, JTCMLS is the incremental cost and $\partial \mathrm{TE}_{\mathrm{ML} S}$ is the incremental effectiveness of MLS strategy.

The CER criteria demands that, if for example, CER ${ }_{M R C+V C}<C E R_{M R C-V C}<$

$\mathrm{CER}_{\mathrm{CRC}+\mathrm{VC}}<\mathrm{CER}_{\mathrm{CRC}-\mathrm{vC}}<\mathrm{CER}_{\mathrm{MLS}}, \quad \mathrm{MRC}$ + VC strategy ought to be implemented. In other words, other considerations held constant (e.g. equity), the option with the lease CER should be chosen. On the other hand, if $\mathrm{CER}_{\mathrm{MRC}+\mathrm{VC}}=$ $\mathrm{CER}_{\mathrm{MRC}-\mathrm{VC}}=\mathrm{CER}_{\mathrm{CRC}+\mathrm{VC}}=\mathrm{CER}_{\mathrm{CRC}-\mathrm{VC}}=$ $\mathrm{CER}_{\mathrm{MLS}}$, the policy-makers would be expected to be indifferent between the strategies being appraised.

\section{Results}

The direct and indirect costs (expressed in Emalangeni, i.e. the local Swaziland currency) of various distance-education strategies evaluated are presented in Table 1. The direct costs are broken down into recurrent costs (which include personnel, transport, communications, equipment maintenance, annual journal subscriptions, student fees), and annuitized capital costs (which include vehicles, equipment, furniture and buildings). The indirect cost consists of productivity losses due to work and leisure time invested in studies 
under various strategies.

Table 1: Cost of alternative distance-education strategies (in Emalangeni)

\begin{tabular}{|l|l|l|l|l|}
\hline \multirow{2}{*}{ Interventions } & Direct Costs & Indirect Costs & Total Costs \\
\cline { 2 - 3 } & Recurrent & Capital & & \\
\hline MRC $=$ VC & $20,626,368$ & 666,478 & $45,037,289$ & $66,330,135$ \\
\hline MRC - VC & $10,731,816$ & 134,303 & $21,830,882$ & $32,697,001$ \\
\hline CRC $=$ VC & $16,714,906$ & 209,680 & $32,367,094$ & $49,291,680$ \\
\hline CRC - VC & $6,404,762$ & 62,052 & $13,353,267$ & $19,820,081$ \\
\hline MLS & $4,616,727$ & 114,921 & $8,860,867$ & $13,592,515$ \\
\hline SQ & $1,372,815$ & - & $2,846,218$ & $4,219,033$ \\
\hline
\end{tabular}

NB: 1 US $\$=8$ Emalangeni in year 2000

Table 2: Percentage distribution of costs

\begin{tabular}{|l|c|c|c|c|c|c|}
\hline & \multicolumn{6}{|l|}{ Percentage distribution (\%) } \\
\cline { 2 - 7 } & MRC=VC & MRC-VC & CRC=VC & CRC-VC & MLS & SQ \\
\hline $\begin{array}{l}\text { Direct costs as a } \\
\text { percentage of grand total } \\
\text { cost (i.e., 1+2+3) }\end{array}$ & 32.1 & 33.2 & 34.3 & 32.6 & 34.8 & 32.5 \\
\hline $\begin{array}{l}\text { 1. Recurrent organizing } \\
\text { \& operating programme }\end{array}$ & 8.4 & 7.5 & 7.1 & 7.0 & 8.1 & 0.9 \\
\hline $\begin{array}{l}\text { 2. Student fees: } \\
\text { registration, tuition, } \\
\text { supervision, etc. }\end{array}$ & 88.5 & 91.3 & 91.7 & 92.0 & 89.5 & 99.1 \\
\hline $\begin{array}{l}\text { 3. Annuitized capital } \\
\text { costs }\end{array}$ & 3.1 & 1.2 & 1.2 & 1.0 & 12.4 & 0.0 \\
\hline $\begin{array}{l}\text { Indirect costs } \\
\text { (productivity losses) as a } \\
\text { percentage of grand total } \\
\text { cost }\end{array}$ & 67.9 & 66.8 & 65.7 & 67.4 & 65.2 & 67.5 \\
\hline
\end{tabular}

Table 3: Effectiveness of each of the alternative options for delivering distance education programme

\begin{tabular}{|l|c|c|c|c|}
\hline \multicolumn{1}{|c|}{ Interventions } & $\begin{array}{c}\text { Target } \\
\text { population } \\
(\mathbf{N})\end{array}$ & $\begin{array}{c}\text { Proportion of } \\
\text { target population } \\
\text { enrolled (P) }\end{array}$ & Impact (I) & $\begin{array}{c}\text { Effectiveness (E } \\
=\mathbf{N} \times \mathbf{P} \times \mathbf{~ I}\end{array}$ \\
\hline MRC + VC & 4,000 & 0.510 & 0.720 & 1,469 \\
\hline MRC-VC & 4,000 & 0.396 & 0.488 & 773 \\
\hline CRC = VC & 4,000 & 0.550 & 0.550 & 1,210 \\
\hline CRC-VC & 4,000 & 0.312 & 0.372 & 464 \\
\hline MLS & 4,000 & 0.308 & 0.268 & 330 \\
\hline Status Quo & 4,000 & 0.124 & 0.214 & 106 \\
\hline
\end{tabular}


Table 2 shows the distribution of the direct and indirect costs as a percentage of the grand total cost of each strategy. The direct costs account, on average, for $33.25 \%$ of the grand total costs of various strategies. The costs for organizing and operating the programme, student fees (including registration, tuition, supervision, etc.) and capital items constitute, on average, $6.5 \%, 92 \%$ and $1.5 \%$ of the direct costs. On average, the value of work and private time expected to be invested into studies accounts for over $66.75 \%$ of the grand total costs.

Table 3 summarizes the target population $(\mathrm{N})$, the proportion likely to be enrolled $(\mathrm{P})$, the impact (I) and the effectiveness (E) of each alternative distance-education strategy. It is important to recall that effectiveness is a product of $\mathrm{N}, \mathrm{P}$ and $\mathrm{I}$. On the basis of effectiveness alone, the alternative strategies could be ranked as follows: $\mathrm{MRC}+\mathrm{VC}>\mathrm{CRC}+\mathrm{VC}>\mathrm{MRC}-$ $\mathrm{VC}>\mathrm{CRC}-\mathrm{VC}>\mathrm{MLS}>\mathrm{SQ}$. However, it is important to caution policy-makers that decision must be made by weighing the costs against the effectiveness of alternative interventions; thus they should never be based on either cost or effectiveness alone.

Table 4 portrays the incremental cost, effectiveness and cost-effectiveness ratio for each of the five alternative strategies appraised. The distance-education strategies could be ranked in terms of their incremental cost-effectiveness ratios as follows: $\mathrm{CER}_{\mathrm{CRS}+\mathrm{vC}}<\mathrm{CER}_{\mathrm{MLS}}<\mathrm{CER} \quad \mathrm{MRC}_{\mathrm{vC}}<\mathrm{CER} \mathrm{RRC}_{\mathrm{CRC}}$ $\mathrm{vC}_{\mathrm{C}}<\mathrm{CER}_{\mathrm{MRC}+\mathrm{VC}}$. Thus, the analysis indicates that among the five strategies, centralized resource center WITH video conferencing $(\mathrm{CRC}+\mathrm{VC})$ would be the most cost-effective.

Table 4: Cost-effectiveness of each of the alternative options for delivering distance education programme (incremental cost per incremental effectiveness)

\begin{tabular}{|l|l|l|l|}
\hline Interventions & $\begin{array}{c}\text { Incremental } \\
\text { Cost } \\
\left(\partial \mathrm{TC}_{\mathrm{i}}\right)\end{array}$ & $\begin{array}{c}\text { Incremental } \\
\text { effectiveness } \\
\left(\partial \mathrm{TE}_{\mathrm{i}}\right)\end{array}$ & $\begin{array}{c}\text { Incremental cost } \\
\text { effectiveness ratio, } \\
\text { i.e. }\left(\partial \mathrm{TC}_{\mathrm{i}}\right) /\left(\partial \mathrm{TE}_{\mathrm{i}}\right)\end{array}$ \\
\hline $\mathrm{MRC}=\mathrm{VC}$ & $62,111,102$ & 1,363 & 45,569 \\
\hline $\mathrm{MRC}-\mathrm{VC}$ & $28,477,968$ & 667 & 42,696 \\
\hline $\mathrm{CRC}+\mathrm{VC}$ & $45,072,648$ & 1,104 & 40,827 \\
\hline $\mathrm{CRC}-\mathrm{VC}$ & $15,601,048$ & 358 & 43,578 \\
\hline $\mathrm{MLS}$ & $9,373,481$ & 224 & 41,846 \\
\hline
\end{tabular}

\section{Discussion}

This study succeeded in estimating the cost of each of the six distance-education strategies, simulating their effectiveness, calculating and comparing their incremental cost-effectiveness ratios, and recommending the most costeffective option. On the basis of incremental cost-effectiveness analysis criteria, the strategies were ranked as follows: $\mathrm{CRC}+\mathrm{VC}>\mathrm{MLS}>$ MRC - VC > CRC-VC > MRC + VC. Thus, the analysis indicated that from the viewpoint of both the MoHSW and students (who were health workers), it would be more cost-effective to deliver distance education via the centralized resource center WITH video conferencing $(\mathrm{CRC}+\mathrm{VC})$ instead of the other four alternative strategies.

The effectiveness of MRC+VC may have been grossly underestimated by omitting its other potential benefits. The establishment of micro-resource centers with video conferencing facilities in the 5 health centers plus four regional hospitals could potentially have multiple benefits, including: 
1. Improvement in communication

Direct communication between the Minister of Health (and other ministry officials) and all health staff working in both health centers and hospitals. This possibility could potentially serve to further strengthen the rapport between the MoHSW headquarters (HQ) and the staff working in the field. The motivation levels and productivity of staff would obviously improve. Thus, the potential gains in the quality and quantity of services were not quantified.

2. Resource savings.

Saving of time, travel and transport costs currently incurred by staff from health centers and regions visiting $\mathrm{MoHSW} / \mathrm{HQ}$ for consultations and MoHSW/HQ staff making occasional supervisory visits to various health and regional hospitals.

3. Health promotion

The VC facilities could also be used for communicating health education messages (e.g. HIV/AIDS prevention, Expanded Programme on Immunization (EPI), clean water, sanitation, personal hygiene, etc.) to the population served by the health centers and hospitals.

4. Community participation

The availability of VC facilities could also facilitate direct communication between the MoHSW/HQ and the communities served by various health centers and regional hospitals.

5. Health information system

The existence of VC facilities at health centers and hospitals could potentially facilitate the process of updating the MoHSW data bank on health care inputs (e.g. numbers of various cadres of staff, drugs, equipment, vehicles, etc.) and quantities of health services provided (e.g. number of outpatient visits, inpatient admissions, etc.).

6. Disease surveillance

The VC facilities could also be used for monitoring disease patterns and for quick health situation analysis.
7. Planning, monitoring and evaluation

The processes of planning, monitoring and evaluation of health care could be greatly enhanced by the installation of such video conferencing facilities.

8. Inter-sectoral collaboration

Other social sectors (e.g. education, water and sanitation, etc.) could also use the video conferencing facilities to mobilize communities in order to boost literacy levels and water coverage. All such activities would have a positive spillover effect on the health status of the communities.

An improvement of $11.7 \%$ in the effectiveness of MRC+VC strategy, holding its cost and the effectiveness of the other options constant, would make it the strategy of choice. So, the MoHSW policy-makers were advised by the study team that when choosing the most appropriate distance- and continuing-education strategy, they should take into account the above potential benefits of MRC+VC.

Given that none of the other strategies promised such a variety of positive spillover effects, it did not come as a surprise to the research team when the policy-makers eventually chose the MRC+VC strategy.

The MoHSW is currently in the process of developing a project proposal for use in mobilizing the necessary resources to implement the MRC+VC option. Asssistance of external partners may be crucial in meeting the capital costs and issuing fellowships to those interested in pursuing distance-education programmes through DCEP once it is established. Even though it was beyond the terms of reference of this study, the research team developed a questionnaire that was distributed to various development partners located in Swaziland to ascertain their expected contributions towards the implementation of the distanceeducation strategy of choice. Due to the time constraint it was not possible to collect the questionnaire from partners and undertake its analysis. 
Suggestions for further research

The researchers recommended the following activities in the future:

- The questionnaire dispatched to development partners in Swaziland be collected and analysed to establish the form and magnitude of expected support towards the distance-education programme.

- To ensure the sustainability of the distance-and continuing-education programme, it is important to involve at least the ministries of education, Public Services and Information, Development and Economic Planning, and Finance in the final selection of the most appropriate strategy.

- There is need for an economic viability of various ways of financing the distance- and continuing-education strategy that would ultimately be selected by policy-makers in the Government.

- In the African Region, there is a paucity of studies that combines economics and psychology to investigate effective ways in which key health professional could be retained in countries by improving their job satisfaction, maybe through promotion, training, remuneration (salary and fringe benefits), hours of work, patients' satisfaction level, availability of complementary inputs, inequity, cost of living, etc. It would also be interesting to explore the relationship between training, human motivation and productivity.

\section{Conclusion}

According to policy-makers in Swaziland this study had served to clarify the various distanceeducation strategies and their costs and benefits. There is a need for developing in Africa a culture of basing policy and management decision on such types of systematic analysis. Of course, economic evaluation will at most be a guide to policy-and decision-making, and thus, the onus of decision-making will always rest with policy-makers and health-care managers.

\section{Acknowledgement}

The authors would like to thank Hon. Dr. P. K. Dhlamini, Minister of Health and Social welfare, Swaziland, and Dr. T.N.S. Lesikel, WHO Country Representative, Swaziland, for not only commissioning the study but also for providing valuable advice during all its stages of conduct. The multifaceted support of various staff members of the MoHSW (at HQ and health facilities) and the Ministry of Education is greatly appreciated. The editorial support provided by Dr. fidelis Morfaw (Chief) and Mr. AS Kochar, both of PDS unit at WHO/AFRO, is greatly appreciated. We are also grateful for the support provided by the WHO Country Office (Zwaziland) staff during the three weeks the study team was undertaking fieldwork and analysis. This study could not have been successfully completed without the overall guidance and inspiration of Adonai Elohim. The views and opinions expressed here are entirely of the authors and should NOT be attributed to WHO or any of the acknowledged persons/sources.

\section{References}

1. WHO . Fortieth World Health Assembly resolution WHA 40.14. Geneva: WHO, 1987

2. WHO. Forty-second World Health Assembly resolution WHA 42.38. Geneva: WHO, 1989

3. WHO. Forty-second World Health Assembly resolution WHA 42.27. Geneva: WHO, 1989

4. WHO. Forty-fifth World Health Assembly resolution WHA 45.5. Geneva: WHO, 1992

5. WHO. Forty-eighth World Health Assembly resolution WHA 48.8. Geneva: WHO, 1995

6. WHO. Forty-ninth World Health Assembly resolution WHA 49.1. Geneva: WHO, 1996

7. WHO/AFRO. WHO Regional Committee for Africa resolution AFR/RC39/R5. Harare: WHO, 1989

8. WHO/AFRO. WHO Regional Committee for Africa resolution AFR/RC39/R10. Harare: WHO, 1989

9. WHO/AFRO. WHO Regional Committee for Africa resolution AFR/RC41/R9. Harare: WHO, 1991 pp. 
10. WHO/AFRO. WHO Regional Committee for Africa resolution Afr/RC48/R3. Harare: WHO, 1998

11. WHO/AFRO. Regional strategy for the development of human resources for health (AFR/RC48/10). Harare: WHO, 1998. pp.

12. Munguti ND and Kirigia JM. Human resources health-related quality of life: $\mathrm{A}$ case study of Groot Schuur Hospital in South Africa. African Journal of Health Sciences. 1998; 5(3-4):185-189.

13. WHO. The World Health Report 2000 Health systems: improving performance. Geneva: WHO, 2000.

14. WHO/AFRO. Health-for-All Policy for the $21^{\text {st }}$ Century in the African Region: Agenda 2020. Harare: Zimbabwe, 2000. pp.

15. Graham HT and Bennet R. Human resources management. London: Pearson Professional Limited, 1998.

16. Shields MA and Ward ME. Improving nurse retention in the British National Health Service: the impact of job satisfaction on intentions to quit. Public Sector Economics Research Centre, Department of Economics, university of Leister, 1999.

17. Steyn PJN. The feasibility of suing distance education for the training of health care professional in Swaziland. Mimeo. Bureau for University Teaching. University of South Africa, 1998.

18. MoHSW. Training needs assessment. Mbabane: Swaziland Ministry of Health and Social Welfare, 2000. pp.

19. MoHSW. A framework of agreement on: distance and continuing education programme for MoHSW. Mbabane: Swaziland Ministry of Health and Social Welfare, 1999.

20. Drummond MF, Stoddart GL and Torrance GW. Methods for the economic evaluation of health care programmes. Oxford: Oxford University Press, 1990.

21. Kirigia JM, Fox-Rushby J and Mills A. A cost analysis of Kilifi and Malindi Public Hospitals in Kenya. African Journal of Health Sciences. 1998; 5: 79-84

22. Steyn PJN and Human Sp. Consultancy with the division of research and human resource development of the Ministry of health,
Eritrea. Pretoria: University of South Africa, 1999.

23. PictureTel Corporation. PictureTel 900 Series - Video Technology. White paper. Andover: PictureTel, 2000.

24. Dimension Data. Video conferencing Equipment Price Quotation. Pretoria: Dimension Data, 2000.

25. Reynolds J and Gaspari KC. Operations Research Methods: Cost-effectiveness analysis. Monograph Series: Methods Paper 2. Massachussets: PRICOR, 1985.

26. Kirigia JM. Economic evaluation in schistosomiasis interventions: using the Delphi technique to assess effectiveness. Acta Tropica. 1997; 64:175-190.

27. Kirigia Jm. Cost-utility analysis of schistosomiasis intervention strategies in Kenya. Environmental and Development Economics. 1998; 3:319-346.

Manuscript was received on: 9 January 2002 Approved for publication on: 10 May 2002 